\title{
Correction to: Constructing National Identity in Canadian and Australian Classrooms
}

\section{Correction to:}

S. Jackson, Constructing National Identity in Canadian and Australian Classrooms, Britain and the World, https://doi.org/10.1007/978-3-319-89402-7

The original version of the book was revised: The Ontarian Prime Minister's name has been updated from 'Davies' to 'Davis' throughout the book.

The updated version of the book can be found at https://doi.org/10.1007/978-3-319-89402-7

(C) The Author(s) 2020 